\title{
Knowledge Management and Management Accounting Decisions- Experimental Study
}

\author{
Afaf Mubarak \\ Faculty of Business Administration ${ }^{1}$, Al Hosn university- Abu Dhabi- United Arab Emirates
}

\begin{abstract}
In this study, the author explores how individuals in the UAE who involve in making management accounting decisions (e.g. planning, investment, allocating resources,...etc) would acquire, distribute and use knowledge. The study replicates the experiment of Edward et.al. (2006) of CIMA project about how knowledge is managed within management accounting decisions. A total of 26 participants from different departments and different industries (hotel, insurance, retail, education, travel and food) contributed in answering questions on cases present routine and strategic decisions. The results indicate that participants do not differentiate between information and knowledge and all organizations have effective methods for collecting and maintaining knowledge in databases, files and other documents and different information are kept and used for the different decisions. In general, contributors in the study tend to reply more on formal, written information both financial and non-financial. However, for strategic decisions the non-financial information from different sources tend to gain more importance. Local respondents and those work in environments which encourage risk-taking tend to depend on informal and oral information more than non-local participants and those in middle management. Knowledge for routine decisions are processed via computerized programs but participants could not explain how they process knowledge in their minds and how they utilize in the different situations. The study revealed that there are differences in knowledge and its management according to industry, managerial level and type of decision and there were reflections of the UAE's business environment with its multi-culture and having specific strategies for example to encourage creativity as in tourism industry or to be tightly regulated as insurance industry.
\end{abstract}

Key words: knowledge management- accounting- experiment - UAE.

${ }^{1}$ The author would like to thank participants of IBIMA $18^{\text {th }}$ conference in Turkey -May 2012 and an anonymous reviewer for constructive comments.

Copyright (C) 2013 Afaf Mubarak. This is an open access article distributed under the Creative Commons Attribution License unported 3.0, which permits unrestricted use, distribution, and reproduction in any medium, provided that original work is properly cited. Contact author: Afaf Mubarak E-mail: a.mubarak@alhosnu.ae 


\section{Introduction}

Since the "relevance lost" of management accounting which has been framed by Robert Kaplan and Thomas Johnson (1987), and the discipline has been addressed from different perspectives and in different ways. The intention is to improve its grounds and to provide better understanding and analysis for the different phenomena it addresses. One of the old and ever visited approaches is to investigate management accounting as an information system and within that approach, to analyze it under specific lenses. One of those latter stands is to examine the decision making process in management accounting with a "Knowledge Management" lenses. While there is no consensus on what knowledge or knowledge management (KM) is, the author referred to a study of Firestone (2001) which surveyed and analyzed a good deal of definitions for both. However, it is not among the targets of this study to evaluate the different definitions of knowledge nor to compare it with data and information or to do the same with KM. Instead, the author will adopt a functional definition of knowledge management that fits with the type of the current study. The aim of this study is to explore how $\mathrm{KM}$ is used in making decisions and to do so, the functional definition will be consistent with the decision making process generally. The definition adopted for Knowledge Management in this study is that it consists of activities focused on the organization gaining knowledge from its own experience and from the experience of others, and on the judicious application of that knowledge to fulfill the mission of the organization. Knowledge management (KM) is the name of a concept in which an enterprise consciously and comprehensively gathers, organizes, shares, and analyzes its knowledge in terms of resources, documents, and people skills. The definition of "Knowledge" adopted is that; while knowledge is made up of data and information, can be thought of as much greater understanding of a situation, relationships, causal phenomena, and the theories and rules (both explicit and implicit) that underlie a given domain or problem."

Knowledge management has been receiving a continuous and growing attention on academic and practical levels. On academic level, it is at the top of themes of discussion in most conference of business and information systems. In addition, many journals and publications are allocated to examine KM from different perspectives e.g. Taylor 2006, Benbya 2008, Maier 2007, Bhatt 2001. Examples of discussing accounting and KM, are O'Leary (2002) who wrote a chapter about knowledge management in accounting and professional services, Brikett introduced as early as 1995, a case study of knowledge management as a framework for studying strategic decisions in accounting and Sori (2009) examined the use of accounting information systems by Malaysian companies and its contribution to the knowledge management and strategic role in the organization. Bhimani and Roberts (2004) raised a question about intelligibility in management accounting and knowledge management and Sabina-Cristina (2007) paid an attempt to model accounting decisions relates to fixed assets within knowledge management, study applied in Romania and Booth et.el. (2009) examine two factors that impact managers' willingness to share private information (which is one step of knowledge management activities) during the project review stage of capital budgeting. On practical levels, companies seek to provide training programs to their employees in how to manage their knowledge effectively and also they request consultancy advices about how to build up effective KM systems and Business environment in UAE is not an exception of that. The following section highlights why I chose to study this topic in this country.

\section{Why KM in the UAE}

$\mathrm{UAE}$ is a case of emerging economy that although rich from oil exporting, tries to diversify economic activities. The country tries to move away from depending on a sole 
source of income which is oil, by expansion off-shore in some activities such as telecommunications, construction, retail and leisure industries. In doing so, businesses (private and public drive their steps by adopting most up-to-date international business practices and one of that is to build up a supportive knowledge management systems. Just examples of concern are; the conference of "KM Middle East, 13-14 March 2012" in the capital city of Abu Dhabi and "UAE e-Government Employee Knowledge Management Development Conference" Dubai 5-7July 2011 and "International Human Resources Conference- Knowledge Management: Challenges and Applications in the GCC" 19-20 January 2011 Dubai-UAE. The second conference reflects an intention to imbed KM into the development of egovernment in UAE and the latter one apparently focused on KM practices and improvements within the region of Gulf Cooperative Council (GCC) to which UAE belongs.

KM gains a special importance in UAE for particular reasons as the author noticed. First, there are giant businesses with billions of dollars resources (e.g. Etisalat telecommunication had total assets of $20 \mathrm{~b}$ dollar and size of operations about $11.8 \mathrm{~b}$ dollar in 2011 and operations in 17 markets; Emmar for real estate has total assets of 17.3b dollar in 2010 and operates in many countries in MENA, Europe and Asia). Reexport valued more than $60 \mathrm{~b}$ dollar according to the National Bureau of Statistics in UAE in 2010. This suggests that there are huge body of knowledge have to be run effectively and efficiently and it is expected that a reliable management of knowledge is a key factor of success here. Secondly, UAE is known to have business relations with many countries around the world (as indicated in the case of Etisalat telecommunications which operates in many countries including Egypt, Saudi Arabia, Sudan, Tanzania and others, Emmar operates in Egypt, Morocco, UK, Asian countries and the global holding company Dubai World works in Transport \& Logistics, Drydocks \& Maritime, Urban
Development, Investment \& Financial Services, its portfolio extends from the Americas to Asia including India, China and the Middle East). Doing work in and with foreign countries -in addition to the government's genuine initiative to build a modern country- urged UAE to adopt the most modern and up-to-date business practices in every aspect; e.g. corporate governance, disclosure practices and KM. The third reason in my view is the fact that most of the work force in UAE is expatriates who came from different countries for work. According to Bureau of National Statistics, the foreign employment makes more than $60 \%$ of the work force from many countries of which $80 \%$ are Asian, 15\% Arab and the remaining belong to different countries. Having a business environment that is multiculture raised the importance of having smooth and effective methods and tools for communicating and distributing knowledge among co-workers to help them work, cooperate and create more smoothly at work.

\section{Knowledge Management and Decisions' Making in Accounting}

While there are many dimensions in KM topic to be discussed, the focus in this study is on knowledge management while making decisions in management accounting domain. Accounting plays different roles in organization. In base, it is an information provider to decision makers and in doing so, accounting follows set of steps include collection of its own information, analyze and organize those information and suggest or recommend a solution or alternative. Accounting does involve in many types of decisions for example; planning by preparing budget, evaluating performance, measure costs and revenue, run sensitivity analysis for volume of production, costs and profit, making investment decisions and others. When accounting is doing its functions, it generates, stores, analyze and utilize a body of "knowledge" that is added to the overall knowledge of organization. The purpose of this study is to explore how accounting information are developed and 
used as part of the body of the knowledge of the organization. It is known that accounting helps is providing information to different users; internal and external to the organization and for different decisions; operational and strategic.

Wilkinson (2000) considers the management team that consists of Finance General Manager, Chief Operating Officer, Managing Director and Board of Directors are among the internal users of the system. On the other hand, the external users consist of government agency (e.g. tax authority), external auditors and creditors. Indeed, wide variety of people within and outside the organization uses accounting information for decision-making. Accounting information contribute to the profession's value added to the organization. In addition different decisions are supposed to have specific needs of information. Courtney (2001) reviews various studies that debate how organizations manage knowledge with the purpose of developing some decision support system. It could be viewed from different perspectives, procedurally knowledge is created in the heads of people, captured and put on paper, in a report or a computer system or a library. Then knowledge is classified or modified so that it can be restored by others. When knowledge is reused, a new knowledge may be created by putting it into new context, background or into new analysis. This is valid especially in social sciences such as accounting where knowing and knowledge are inseparable from action. Knowledge is viewed as an object and an action and organizational knowledge is viewed as a "collective mind" developed through interpretation, communication and shared meaning.

Sori (2009) argues that both tacit and explicit knowledge are used as shown by the extensive used of accounting information system to assist business decision-making. While there are different jobs for management accounting, and hence different contributions of accounting information and different processes for this information, this research targets to examine how knowledge is collected, processed, distributed and utilized in different decisions' situations; ranging from routine to strategic decisions and their needs of information and possible outcomes. Chou et.al., (2008) illustrate that accounting is developed to demonstrate an architecture of ontology. the development of accounting ontology presents a framework for building accounting knowledge and may also serve as an excellent learning tool for accountants. According to the writers, the process of constructing the accounting ontology, consists of 5 stages: Collect Accounting Information, Analyze Accounting Items, Accounting Item Taxonomy, Import Accounting Items to build up interrelations and Generate Ontology for Accounting to develop the acting architecture. The researcher states that this presentation by Chou et.al. (2008) introduces accounting as a body of "knowledge" in organizations that is developed and used in a way quite similar to that of the general KM activities highlighted earlier and this proves the consistency of the research phenomenon (Management accounting decision) and the framework of analysis (which is Knowledge management) selected in this study.

This study is a kind of replication to the essence of the CIMA research about 'Knowledge Management and its impact on the Management Accountant" by Prof John S Edwards, Dr Paul M Collier and Dr Duncan Shaw published in 2006. The reasons for this duplication stem from the functions which a replication study could fulfill. Thomas (2003) states that a replication study is designed to perform one of four functions: (1) To assess the results of an earlier investigation in order to confirm or disconfirm the reported outcomes of that investigation, (2) to judge how stable the results have remained with the passing of time and to estimate the causes of any changes that occurred, (3) to alter some aspect of the earlier methodology in order to discover what effect such alteration has on the outcome, (4) to apply the earlier method to a different group of people or different set of events in order to 
learn whether conclusions derived from the earlier study apply equally well to those different people or events. The author believes that functions 1 and 4 mentioned by Thomas are valid in this study. I hoped to test whether the Western-run study of CIMA would provide the same results if repeated in an Arab environment that is described as still developing, has its own culture, practices and its own features. Secondly, I am deliberately interested to find out impacts of some factors in this study such as business environments' of making accounting decisions on the process of knowledge management. Variables of consideration include type of decision (routine or non-routine), needs from information (financial and nonfinancial, facts, rumor, ...etc), type of industry and impacts of managerial level, business strategy and culture. In conclusion, the contribution of this research would develop from:

a- Doing a replication of a previous study to examine what/how knowledge is obtained, processes, shared and stored in an environment different from the original study (which is the UAE) and on different participants (middle and senior managers from different industries).

b- Examine if specific factors of concern (industry, managerial level, type of decision, strategy and cultural issues) may affect the activities of managing knowledge. This line of investigation was not covered by the original study.

c- Collecting feedback on the research questions directly from individuals -in the different industries- involved in making decisions would reveal if the process of acquiring, processing, sharing and storing knowledge done by organizations is relevant, adequate or not, to what extent, suggestions from participants regarding any developments.
In this research, the focus is on arguments around knowledge management activities within making accounting decisions. The research focus could be formatted into the following themes:

- What is knowledge required for management accounting decisions? Links to information?

- How this knowledge is collected? From which sources? In which format?

- How this knowledge is processed both in the organization's information system and in users' minds? How shared (formally/informally)? How stored?

- What are the effects of type of decision, type of industry, strategy and culture on knowledge management?

\section{Research Methodology}

In order to explore the research themes, the author selected to use a semi-structured experiment. Experiment is suggested by Christensen et.al., (2011) to be used in examination when there is a need to "observe" specific outcome and test a phenomenon under specific conditions. An experiment allows the investigator to employ standardized procedures to investigate the effects of treatments. Such standardization ensured a high internal validity or the ability to attribute findings and this is this is the target in this research. As explained earlier, the UAE is a multi-culture business environment, expanding and has links overseas. Therefore, I intend to explore how individuals involved in accounting decisions such as planning via budgets, measuring costs, preparing financial information and investment decisions, how they collect, distribute, share and use information relate to those decisions. 
While there are different types of experiments (true, repeated-measures designs, quasi-experiments, and time series designs). Internal validity is generally highest with true experiments due to the random assignment of subjects to different treatments. Conducting experiments is facilitated by following a systematic planning and application process. A seven-step model suggested by Christensen et.al., (2011) consists of (1) selecting a topic, (2) identifying the research problem, (3) conducting a literature search, (4) stating research questions or hypotheses, (5) identifying the research design, (6) determining methods, and (7) identifying data analysis approaches. In my study, the participants are allocated randomly and a true experiment is run.

Because the author had no access to the research instruments of the original study, she intends to investigate the knowledge management practices when taking decisions in management accounting in different industries in UAE. Using a semi structured experiment, the author targets to examine how the jobs of knowledge management ranging from knowledge collection, classifying, processing and distribution are applied? Are there differences between doing these jobs for a routine decision and a strategic decision? What type of information relates to each, financial, technical,...etc? How information flow, formally, informally? What are the sources of knowledge, internal, external? What do information relate to: people, business solutions or processes? And is there an impact of managerial level of decisions maker on this debate?

In order to collect data, eight workshops were held with accountants and managers from different departments and at different levels. Participants belonged to organizations that works in different industries and of different types (governmental, public and private) works in both the capital Abu Dhabi and the tourism well-known city and what was the economic capital (before the international financial crisis) Dubai. The number of organizations and industries they work in are:

-Municipality (1)

-Insurance (2)

-Hotel and Leisure (1)

-Retail (2)

-Travel (1)

-Food and beverage producing (1)

-Education (1)

Participants are deliberately chosen from different nationalities as this element could make a difference in the participation of creation, distribution and utilization of knowledge. As mentioned in the earlier introduction section, the National Bureau of Statistics in UAE announces facts about the diversity of workforce in the country and the domination of expatriates. To take this fact into account, participants were chosen from different nationalities, of the total 26 participants, 6 were Emirates, 8 Western, 7 Arabs and 4 Asian. This distribution is not consistent with that of the overall population of workforce mentioned in the introduction. The reason for the difference relates to managerial level. Participants were targeted to be working in middle and senior levels and those are largely filled up with locals, western and Arabs. Given that decisions in management accounting are undertaken not only by accountants but also personnel from different departmental functions involve so participants in this experiment will be working in different departments.

Each workshop included a group of 3-6 participants from the same company with total of 26 participants in 7 sessions. Each group was allocated two jobs; one is a case of a 'routine" planning budget and another job that is rather "strategic" relates to capital investment. Data were collected on a questionnaire with many open questions 
where participants were asked to record on a computer their evaluation for the case, record their needs of information if they are involved in this decision in reality, they were also asked to classify their needs of information if financial or non, technical or general, relates to regulations or procedures and processes. The participants were also asked to highlight the source of the information they need, internal or external.

This method of collecting data and to enrich the data, the researcher depended on interviews implemented while participants are answering questions. The researcher distributed questions and recorded notes for answers and in the mean time, kept answering enquiries about what is the meaning of a point or another and what is required clearly here or there. The researcher spent a specific effort to attract the attention of participants to report about how they get the information they need for their decisions, how such information are organized by their companies, how communicated and the degree of utilizing those knowledge and information. In answering all questions, participants were encouraged to record all their thoughts, ideas, notes,...etc on the light of their real experience as much as possible. After getting answers, the researcher tried to map what the points of agreements and points of differences between participants and whether some differences stem from difference in managerial level, type of decision or type of organization. The following section reports the key findings and will include a comparison with the results of the original study of Edward et.al. (2006) as well as with studies which examined the same or similar themes in the literature.

\section{Research Findings}

The following dimensions could be identified from the participants' feedback:

\section{I: Features of Knowledge}

- Differentiation between information and knowledge

- Type of information used: financial, nonfinancial, technical, facts, rumors or judgment

- Format of information: formal, informal, raw or processed and written or oral

- Source of information: internal, external

II: How knowledge is managed:

- How acquired: specific forms/format, databases and other stores

- How processed

- How distributed and shared

- How used

\section{I: Features of Knowledge}

\section{- Differentiation between Information and Knowledge}

Almost all participants seemed not concerned with differentiating between data, information and knowledge. One reason was given by a production supervisor in food manufacturing is that users tend to use "information" that has been used before by others, that result from calculation of expected sales in the coming quarter, "would this be "information? Or data? Or knowledge to me? I don't care, I need that piece of information to be available for me when I need to build up my production schedule accordingly". In insurance company, policy processor officer records that he needs all regulations and decrees that govern his work to be clear and available although he is aware that those information resulted from discussions and meetings among senior managers who draw the broad lines for the business. So when he uses the previously processed information is it information or data or knowledge? One participant from municipality states that: In doing my work, I 
consciously or subconsciously re-call different pieces of information, data, knowledge which I "carry in my mind" in addition to what I use from regulations and past experience documents, and I apply all that in the situation. A students' affairs' manager in an educational institute considers "knowledge" is "what is stored in our mind not only data and information we got, but how we processed, what relationships, evaluations, speculations and predictions we make, this is affected by our personality. Therefore, you could teach two people the same information, one may remember all the details, make links, summarizes and generates new knowledge which he/she uses in a way different from the other person. This lack of distinction between knowledge and information somehow also appeared in the original study by Edward et.al. (2006) and when a differentiation was made, participants considered information as a commodity while knowledge is part of the intellectual capital of the organization. Participants in the latter study also saw that there is a great deal of information and knowledge exist in organizations but not well-managed or shared even with the use of email or meetings because wrong people are communicating or being run ineffectively.

The author finds the lack of a clear distinction mentioned, is consistent with the definition of knowledge adopted in this study and presented in the introduction section. That is, knowledge, includes raw data, processed information and experiences used in a situation. The previous views mentioned by participants miss a point, that any "information" could be "data" in a further processing operation. Therefore, in the remaining of this section, no distinction will be made between data, information or knowledge.

\section{Type of Information Used}

Participants report different types of information they use in their job, according to everyone's field of work and to type of decision undertaken. For example, participants in finance and accounting departments depend largely and mainly on financial measures relate to costs, revenues and values of resources. However, marketing manager in retail company is concerned not only with the amount of sales but also the distribution of those sales over seasons. He explains: "We are working in a country where shopping is a genuine habit to the Emirati people and to the expats. The Empirati loves getting new items in festivals, occasions and when going for holidays. Expats' high purchase season is in summer when they go home. They love to take presents to family and friends from their host country. I can't confine sales to those seasons, my target is to promote sales all over the year and I try to provide different techniques of promotion, therefore I depend on related-products, promotion for volume of sales, introducing different prices....etc, so financial and non-financial data are important to $m e$ ". In insurance company the officers of processing policies highlight that different databases exist in their system; databases for customers, items insured, cost of insurance, compensation paid under each policy and records for damaged happened during each policy. In hotel, events and banquet manager maintains organized files for customers, events and their requirements as per customer's specification and steps executed in each event, his resources in-house and resources that can be outsources and details of them. For this manager, financial information such as prices and costs are of limited importance (only needed to price the contract). An engineer works as deputy road maintenance of an area of Abu Dhabi revealed that data he uses are only technical, those relate to establishing new roads, extension or expansion to existing ones or maintenance of old roads. All his work is expressed in technical terms, his "plan" on work is measured in kilometers of roads to be built or maintained in the year and resources needed are also measured in technical resources. This engineer highlights that even translating his budget to financial terms is done not by himself but by an accountant with old experience in the construction field. The result that can be reached here is that for 
decisions in different industries, there are different types of information needed and that information constitute the body of knowledge that should be captured, organized, disseminated in each sector in both financial and non financial terms. This result agrees with Sabina-Cristina (2007) on knowledge management of some accounting decisions, study applied in Romania. SabinaCristina (2007) found that knowledge of making accounting decisions is strictly specific to those decisions, with an emphasize on qualitative knowledge and participants acted based on knowledge in broad context of making decisions not looking at optimization.

In all cases, participants confirm that their organizations have organized databases and well structured files with data about customers, employees, suppliers, costs and prices, payments and revenues collected or charged to customers. Some businesses stress the importance of specific type over others. For instance, in insurance field, a respondent emphasized the importance of regulations and policies saying: We are tightly regulated field. Prices, premiums, conditions of each policy are by large regulated from the supervising authority. We have a limited margin to "look different" from other companies. Therefore, regulations and guidelines are major part of information we refer to when working. Unlike this sector, the education representative record his delightfulness that there is lots of demand for academic qualifications. In UAE providers of such qualifications are interested in providing different programs and promote what their institutions have as competitive advantages. The information about the courses and facilities provided, are crucially important. Hotel and leisure is a flexible industry looks for creative ideas and thus has different concerns for knowledge. Respondents from this field considered information about promotion package, prices, quality of services are in the main focus when taking decisions. Participants highlight that "Dubai particularly became an iconic destination for holidays and many hotels are there, so competition is intense. Every place wishes to attract guests by promoting an advantage; it could be price, attraction of destination, variety of services provided and so on. Information about innovative ideas create money, new ideas are well appreciated in our field".

It depends on the type of decision how much financial or non-financial data are used in a decision. It also depends on the nature of the decision whether it is operational or strategic, that detail-related information are used or "overall" information, technical or managerial, are used as with strategic decision like opening new branch or purchase another business. However, users of information highlight a fact that, information, or knowledge they use do not depend only on "raw data" as those stored in databases, it also needs regulations, management decrees and policies, discussion with co-workers in other departments. Very often users face complicated situation, where to resolve, they use: stored data, related regulations or policies and use their own judgment as well. Therefore, there is no inclusive list of information items that relates to a decision.

The author find the participants' feedback generally in line with the literature of accounting information systems (e.g. Romney and Steinbart 2009) where it is decided that there are different information needed for each decision and it depends on the nature and scope of the decision whether the information will be detailed or general, financial only or both financial and nonfinancial, related to a specific unit or to the overall organization. It is not only the nature and scope of decision but also the type of industry that clearly affect choices and preferences of knowledge to be gathered, maintained and utilized.

\section{Format of Information}

When participants were asked about the format of knowledge they use in their decisions, they all respond that the formal 
body of knowledge is the main one used, comes from databases, policies and regulations, previous business cases and others. Contributors in the experiment reveal that they do not exclude informal information passed by colleagues chat or from the media or any speculations here or there. Hearing a rumor if not taking into account when considering a decision, could rise the level of risk relates to a decision. Nonetheless, evaluating an informal information as strong or weak and influential or not, depends of the recipient's view and his/her attitude towards risk. This result is rather different from the one in the original study by Edward et.al. (2006). In that study, participants placed greater reliance on individual and informal systems although they wished to move more to the formal system. The reason they presented was that the informal knowledge system is rich but the formal is more robust and consistent which enhances shareability.

The author argues here that because the majority of work force (and hence the participants) in UAE are non-locals could be the reason for the higher tendency to rely on formal versus informal and written versus oral information. In this study, it is observed that the vast majority of applicants prefer the written format. One evidence is provided by a participant in food and beverage producing comments: I make sure that I keep a copy of any email to customer, supplier,...etc or copy of an invoice or purchase order to defend my decision in any case. Another respondent in municipality added: If I am in a situation which is new or complicated to me, I use my judgment, I prefer to communicate with my manager about it, however, I take the decision on my own, if I am sure of it, ultimately I do not want to cause any harm to my organization. The writer considers these views actually reflect sharing of responsibility and different risk-taking more than an organizational culture. Informal information no matter how important, are not evident to be used on a wide scale. This result agrees with the argument of DeLong and Fahy (2000) that culture influences the behaviors central to knowledge creation, sharing and use. Culture shapes assumptions about what knowledge is, which knowledge to be managed and defines the relationship between individual and organizational knowledge. Moreover, it determines who is expected to control specific knowledge. Contributors in this experiment who are mainly non-UAE citizens, seem to prefer to avoid risk and to justify their decisions based on solid evidence. In their view, that evidence exists mainly in "written" and "formal" information. This relationship maybe mandated by managerial level. Most of the participants belong to middle management from whom the result appears. It may be possible to have a different result if individuals were from senior management with more risk taking.

\section{Source of Information}

Respondents were asked if they get their knowledge from internal or/and external sources. All sources are in action in UAE business environment. All respondents report that they have organized internal sources for knowledge including, formal IT systems with databases, documents, emails, regulations and policies, discussions with managers and colleagues. Outside the organization, there are conferences, workshops, exhibitions and other events in addition to magazines, customer surveys, news, words from friends ...etc.

In fact the internal sources is the first and the main source for information for the different knowledge for different situations. However, work environment is known to be a very open environment in terms of organizational learning. Almost all respondents report that generally they "learn" from many sources; formal training courses, workshops and conferences which companies send employees to. Almost all organizations are actively involved in a wide range of events that take place in the country all year through, even if not related directly to their own operations. For example, any small or medium size organization would receive 
invitations to conferences that may relate directly or indirectly to their work for free. The availability of suck opportunities largely enhance the knowledge of employees and provide big chances to outreach different audience and customer or business partners. Participants from travel agency, hotel and food producers for example mentioned that they attend -at least- the annual international conference about travel and leisure management that is held in Abu Dhabi National Exhibition Center in addition to many others in Dubai. In this field, participants recorded that leisure and hospitality industry is every changeable and developed very fast and it is import to follow up what's new there. Those opportunities allow agents to introduce their companies and their services to customers from all over the world, it is a handy. Emirate of Dubai is particularly very active in that domain.

Regarding technical knowledge, engineer in municipality mentions that his work place invites experts in the field to enrich and refresh their knowledge in the modern methods used in his field. The municipality as a governmental unit believes that investing in people and developing their knowledge will certainly be reflected in the way of doing the work, it may improve quality, reduce time, help attendees to provide new and innovative ideas. Costs for workshops, conferences, specialized events all will pay at the end.

\section{II: How Knowledge Is Managed: How Knowledge Is Acquired, Processed, Shared and Used}

All applicants report that their knowledge is gained over time and from experiences they pass in various situations. As mentioned earlier the definition adopted in this research for knowledge is that, the body of items maintained collectively in our minds. It includes data, information, facts, speculations and the new information developed from connected and analyzed information. Some participants referred to this meaning of knowledge in participants' minds. In addition, respondents recorded that there are formal methods for gathering information in their organizations. Participants mention that "no organization could live without a memory". Information and knowledge are stored in databases and organized files. Those form the memory of the organization. It contains information about customers, suppliers, employees, costs, revenues, assets and liabilities and resources owned. Both financial and non-financial information are collected over time and stored. Previous business operations (sales, purchase, investment,....etc) all are part of the body of knowledge of the organization. It includes different types of knowledge, raw data (e.g. contact information of customers, staff,..etc), information (i.e. processed data such as: purchase order executed, computation of net income of a branch or a type of product done before), regulations and policies (those could be in email or statement,...etc). business plan, vision, mission,...etc. For organizations, knowledge is collected in files, documents, databases, emails and informally colleagues discussions or media and publications.

Regarding knowledge processing, contributors in the study found it very hard to explain how they "process" or "use" knowledge in their minds. It is a mental and psychological individual process that differs from one person to another. People could not explain, only psychology and brain-work discipline could tell how this process and the process of utilizing knowledge occur. But participants report that organizations process only formal information and knowledge in specific ways. Regarding accounting decisions, finance officer in retail company mentioned that they use an Oracle package of accounting, where they can not only build up budget but other accounting models such as recording transaction, preparing financial statements and keeping information about customers and purchases and payment and suppliers, sales and collection of payment when inputting data. Similar remark was made by other participants in municipality and other 
organizations. A participant in insurance with a former experience in police department mentioned that in his previous workplace they were using Peach Tree accounting software. Other programs like the Indian-developed programs were there in practice. The results are consistent with those of Edward et.al. (2006) where found all examined organizations have effective methods of acquiring information but not in sharing and utilizing them and that was everyone's problem not only top management. The latter study also record a difference in view between the organization and employees. Organizations focus on technical solutions concerned largely with making better use of databases and intranet while people are concerned with staff retention, motivation training and networking and hence they wish to have KM systems to do so. They conclude that most (if not all) KM initiatives in organizations will not succeed unless it is backed by people who have access to sufficient resources to make it work. Edward et.al. (2006) make an important conclusion here, if these changes are made, organization would move from being information-based, to intelligence-led and this needs a supportive culture including a strategy/framework for KM.

One note the author makes here is that, all organizations have computerized systems for gathering and storing formal knowledge and for processing routine jobs only. The contrary is also true and by participants' support. Respondents mentioned that strategic decisions are more complicated and while based on both overall financial and non-financial data being analyzed in some ways, they are also extensively discussed between members of higher management and maybe with the help of external expertise. Those decisions include much of management's evaluation and assessment of many factors and maybe guided by similar and other cases in other businesses.

Regarding sharing of knowledge, participants confirm that a healthy organization would promote sharing of knowledge. The way this happens differ from one place to another. In hotels, participants mention that when they face an unusual situation, they enquire from more experienced member who should share their knowledge for the sake of the benefits of the company. In municipality, individuals feel they are more responsible for decisions that affect businesses and individuals in $\mathrm{Abu}$ Dhabi (involving in giving a business license, inspections on businesses,...etc). This appreciation of responsibility makes the individuals seek colleagues and senior members advice or guidance when facing uncertainty. Participants from municipality report: "Individuals involved in a decision can call for a meeting by an email to exchange views with related co-workers and straight away a meeting could be held to discuss the issue of concern". However, companies avail databases, files, models and format, patterns and previous operations' files and maintaining copies of documents are formal means for sharing knowledge. Those methods represent methods of sharing knowledge. The researcher would regard the result here to be generally in line with O'Leary (2002) who considers that ultimately the value-added from knowledge management can only be known if effective processes are in place to facilitate control, value assessment, and being cost-effective and businesses need some evidence or measurements on a financial return for the use of KM. Measurements may include issues like time spent in collaborating, percentage of group work, extent and complexity of network connecting knowledge.

\section{UAE Environment's Implications on KM}

There are some issues from previous findings that highlight business environment in the UAE and its implications on KM. First, regarding knowledge to be captured and managed, participants report that the emphasize which the government places on tourism, raises the importance of collecting and processing information about quality and innovation in that field whereas, the financial services sector generally and insurance specifically is a tightly regulated 
sector, so information about rules and regulations are more important. Another feature in this country is about the huge inspiration toward getting a higher education degree. This feature motivates education institutions to collect, maintain and distribution more information about degrees and their requirements. Non-local employees in the UAE tend to prefer to depend on written information more than oral which locals feel more confident to use. However, it is evident that the UAE is an ambitious country and achieved a great deal of advances in services to people. This feature is reflected in the existence of computerized and well organized methods of collecting, processing, sharing of information and using by employees from different backgrounds added to the value created via KM systems. Another unique feature of the UAE relates to being a rich oil producer country with small population and a willingness to enhance knowledge and skills of people, it was vast reported that many conferences, workshops and seminars are available which helps in creating and sharing knowledge in different functional areas. These huge resources of companies and sometimes the international requirements which some supervising bodies urge organizations to follow, lead to develop staff standards. This is a feature to be counted for KM practice in the UAE that may not be observed in a country that experience limited resources or struggle under financial crisis. The last feature in business environment in all GCC and the UAE is being multi-culture, it was obvious in this study that having different minds enrich knowledge being created and managed in an organization. It is well known that the UAE is a demanding place in terms of qualifications and experience which work places require to hire staff. This result in enriching amount and quality of the body of knowledge which an organization works with. Such a feature may not be present in a closed society where individuals rarely work with colleagues and managers with different experiences.

\section{Conclusions}

This research targets to examine how participants from organizations in UAE acquire, share and utilize knowledge. The findings show that participants do not differentiate between information and knowledge. Results show that all organizations have effective methods of acquiring knowledge in databases, files and other documents and different information are kept and used for the different decisions. Knowledge are processed in computerized programs but how participants could not explain how they process knowledge in their minds and how they utilize in the different situations. The study revealed that there are differences in knowledge and its management according to industry, managerial level and type of decision. there were reflections of the UAE's business environment with its mutli-culture and having specific strategies that encourage tourism industry and tightly regulate insurance. The results of the study are limited by the choice of experiment primarily as a method of investigation and by the number of participants, their experience and the fields they work in. The study was concerned to explore specific points, other elements are missing such as how the knowledge is generated and how used by participants.

\section{References}

Benbya, H. (2008). Knowledge Management Systems Implementation: Lessons from the Silicon Valley, Oxford, Chandos Publishing.

Bhatt, G. (2001). "Knowledge Management in Organizations: Examining the Interaction between Technologies, Techniques and People," Journal of Knowledge Management, Vol. 5, No.1, PP:68-75.

Brikett, W. P. (1995). 'Management Accounting and Knowledge Management,' Management Accounting, Nov. PP: 44-48. 
Cheng, M. M., Schulz, A. K.- D. \& Booth, P. (2009). "Knowledge Transfer in Project Reviews: The Effect of Self-Justification Bias and Moral Hazard," Accounting and Finance. Vol. 49 No. 1, P:75.

Chou, T. H., Vassar. J. A. \& Lin, B. (2008). "Knowledge Management via Ontology Development in Accounting," Kybernetes, The international journal of cybernetics, systems and management sciences, Vol. 37 Iss: 1, pp.36- 48 .

Christensen, L. B., Johnson, R. B. \& Turner, L. (2011). Research Methods, Design and Analysis, 11 ed., Pearson.

Courtney, J. F. (2001). "Decision Making ad Knowledge Management in Inquiring Organizations: Toward a New DecisionMaking Paradign for DSS," Decisions Support Systems, Vol. 31, PP: 17-38.

De Long, D. W. \& Fahy, L. (2000). “Diagnosing Cultural Barriers to Knowledge Management," Academy of Management Executive, Vol. 14, No. 4, PP: 113-127.

Edwards, S. J., Collier, P. M. \& Shaw, D. ( 2006). 'Knowledge Management and its impact on the Management Accountant,' Research Report for CIMA, UK.

Firestone, J. (2001). 'Key Issues in Management Knowledge,' Knowledge and Innovation: Journal of the KMCI, Vol.1 No.3.

Kaplan, R. S. \& Johnson, H. T. (1987). 'Relevance Lost: The Rise and Fall of Management Accounting,' Harvard Business School Press.

Maier, R. (2007). "Knowledge Management Systems: Information And Communication Technologies for Knowledge Management," 3rd edition, Berlin, Springer.

National Bureau of Statistics in UAE (2010).

http://www.uaestatistics.gov.ae/ReportDeta ilsEnglish/tabid/121/Default.aspx?ItemId=1 923\&PTID=104\&MenuId=1, as checked in $20 / 2 / 2012$.
O'Leary, D. E. (2002). "Knowledge Management in Accounting and Professional Services," in Researching Accounting As an Information System Discipline by Vicky Arnold and Steve G. Sutton, Published by American Accounting Association.

Roberts, H. \& Bhimani, A. (2004). "Management Accounting and Knowledge Management: In Search of Intelligibility," Accounting research, Vol. 15, No. 1. PP: 1-4.

Romney, M. \& Steinbart, P. (2009). 'Accounting Information Systems,' 11th Edition, Prentice Hall.

Sabina-Cristina, M. (2007). "The Accounting Decisions and their Modelling by Using Specialized Computer-Based Tools," The International Journal of Digital Accounting Research, Vol.7, No.12, PP: 27-51.

Sori, Z. M. (2009). "Accounting Information Systems (AIS) and Knowledge Management: A Case Study", American Journal of Scientific Research, Vol. 4, pp36-44.

Taylor, E. Z. (2006). "The Effect of Incentives on Knowledge Sharing in ComputerMediated Communication: An Experimental Investigation," Journal of Information Systems, Vo. 20, No.1, PP: 103-120.

Thomas, R. M. (2003). "Blending Qualitative \& Quantitative Research Methods in Theses and Dissertations," Sage Publication, New Orleans.

Wilkinson, J. (2000). 'Accounting Information System,' 7th Ed. John Wiley \& Son. 